\title{
Generic Medicine and Generic Prescribing in Nepal: An Implication for Policymakers
}

\author{
Rajeev Shrestha (iD) ${ }^{1, *}$ \\ Sunil Shrestha (iD ${ }^{2,3, *}$ \\ Binaya Sapkota (iD) $4, *$ \\ Santosh Thapa (D) ${ }^{5}$ \\ Mukhtar Ansari (iD ${ }^{6}$ \\ Asmita Priyadarshini Khatiwada (iD ${ }^{2}$ \\ Rohullah Roien (iD) ${ }^{7}$ \\ Akihiko Ozaki ${ }^{8}$ \\ 'Department of Pharmacy, District \\ Hospital Lamjung, Lamjung, Nepal; \\ ${ }^{2}$ Department of Pharmaceutical and \\ Health Service Research, Nepal Health \\ Research and Innovation Foundation, \\ Lalitpur, Province Bagmati, Nepal; \\ ${ }^{3}$ Department of Nursing, Nobel College, \\ Sinamangal, Kathmandu, Nepal; \\ ${ }^{4}$ Department of Pharmaceutical Sciences, \\ Nobel College, Affiliated to Pokhara \\ University, Kathmandu, Province Bagmati, \\ Nepal; ${ }^{5}$ Jeevee Health, Kathmandu, \\ Nepal; ${ }^{6}$ Department of Clinical Pharmacy, \\ College of Pharmacy, University of Hail, \\ Hail, Saudi Arabia; ${ }^{7}$ Medical Research \\ Centre, Kateb University, Kabul, \\ Afghanistan; ${ }^{8}$ Department of Breast \\ Surgery, Jyoban Hospital of Tokiwa \\ Foundation, Iwaki, Fukushima, Japan \\ *These authors contributed equally to \\ this work
}

\begin{abstract}
Generic medicines are being promoted in many countries for their added benefits over branded drugs, such as reduced price, therapeutic equivalence, and convenience to the patients. However, generic prescribing is still not up to the optimum level in Nepal to assure access to costeffective, quality medicines to the public and to reduce the overall economic burden and practicerelated errors of medications. This review aimed to discuss the current scenario of generic medicine, generic prescribing, hurdles on the one hand, and potentials ways in promoting generic medicine usage and generic prescribing in Nepal on the other. Extensive literature on generic medicine usage and generic prescribing practice in Nepal was reviewed. This review found some of the major challenges to be addressed for the proper implementation of generic medicine prescribing, and utilization. These challenges include lack of facilities and competency to assure therapeutic equivalence of different brand-name medicines, lack of understanding about generic medicines among health care providers (HCPs) and the public, and lack of stringent regulation towards promoting generic medicines. Rational pharmaceutical promotion and awareness about generic medication to the medical students are also inevitable towards promoting the practice of generic medicines. The practice of generic medicine and generic prescribing is not possible without the assurance of therapeutically equivalent generic alternatives. The study recommended the prompt effort of the regulatory authority to enforce the generic prescribing and generic substitution policy through strengthening policies, procedures and laboratory testing to assure citizens' right to access to cost-effective, and affordable quality medicine, as the Nepal's National Health and Drug Policy mandated.
\end{abstract}

Keywords: branded generics, brand medicines, generic medicines, generic prescribing, generic substitution, Nepal

\section{Introduction}

Medicine embodies an integral part of healthcare services. The National Health Policy of Nepal, 2019, and the National Drug Policy, 1995 have emphasized on assuring production and access to safe, effective, and quality medicines at an affordable cost. ${ }^{1,2}$ Similarly, the Constitution of Nepal, 2015, declares that every citizen of Nepal has the right to free basic health services, and that no one would be deprived of emergency healthcare services throughout the nation. ${ }^{3}$ Additionally, the United Nations stated that access to quality and affordable medicines is the fundamental element of the right to health. ${ }^{4}$

Currently, majority of the Nepalese population relies on out-of-pocket (OOP) payment for their healthcare expenditure, ${ }^{5,6}$ including medicines due to meager availability of limited essential medicines in a designated government healthcare institutions such as health posts (HPs), primary healthcare centers (PHCs), and
Correspondence: Rajeev Shrestha;

Rohullah Roien

Email rajiv2stha@gmail.com;

rohullahroien@kateb.edu.af 
district hospitals (DHs) at free of cost. ${ }^{7-9}$ According to the Government of Nepal, medical products and medicines are the major (63.4\%) OOP expenditure in Nepal. ${ }^{5}$ Besides, the medicines available in the Nepalese market have wide variations in their price. ${ }^{7,8}$

The cost of medicine is a significant barrier for access to medicines and healthcare services in developing countries, including Nepal. ${ }^{10,11}$ Therefore, low-cost generic medicines with generic prescribing are considered an effective approach in many low- and middle-income countries (LMICs) to reduce medicine expenditure and to improve accessibility and affordability of medicines. ${ }^{11,12}$ Ethiopian studies have reported a positive attitude of prescribers toward generic medicine and generic prescribing ${ }^{13,14}$, however, the generic promotion and generic prescribing are poorly practiced in Pakistan and India, which are neighbours to Nepal. ${ }^{15-17}$ Recently, the drug regulatory authority of Pakistan has made a directive to prescribe medicines in generic names to resolve the medication shortages during the COVID-19 pandemic, which also aligns with the recent findings of a study in Pakistan. ${ }^{18,19}$ Generic medicine has been defined by the World Health Organization (WHO) as a pharmaceutical product that is usually intended to be interchangeable with an innovator product marketed either in the brand name or generic name, manufactured without a license from the innovator company and marketed after the expiry date of the patent or other exclusive rights. ${ }^{20}$ Innovator or originator medicine is generally marketed in brand name and manufactured by the innovator or third companies only under the licensure agreement with the innovator companies. However, comparative effectiveness studies have reported an equivalent clinical outcome of generic medicines to brand-named medications. ${ }^{21,22}$ Similarly, a study conducted among 17 LMICs in 2012 reported that an average of $60 \%$ cost could be saved while switching from originator brands to generic medicines. ${ }^{23}$ Generic medicine is cost-effective compared to the originator product as it does not require undertaking and investing in the protracted research and development process. $^{24,25}$ However, both generic and innovator brand medicines are equivalent and follow a similar pathway for quality evaluation before registration and marketing. ${ }^{25}$

For a long time, generic medicine and generic prescribing have been unresolved issues of discussion in Nepal. Realizing the public health implications of generic medicine usage and generic prescribing, the former policymakers, including the Director-General of Department of Drug
Administration (DDA), the drug regulatory authority in Nepal, and former health ministers, have advocated for promoting the same within the country. ${ }^{26,27}$ This issue of generic medicine and generic prescribing has often considered whenever there was a shortage of medicines and high-price issues regarding medicines in Nepal, such as recently during the COVID-19 pandemic. ${ }^{28}$ However, the discussions on generic prescribing are still an unsolved issue among Nepal's medical and non-medical fraternity. Moreover, there is no previous comprehensive review on generic medicine and generic prescribing in Nepal. Therefore, this current review aimed to discuss the situation of generic medicine and the possibility of generic prescribing in Nepal with a motive of providing valuable inputs to policymakers and healthcare providers towards the promotion of generic medicine and generic prescribing in Nepal.

\section{Scenario of Generic Medicine and Generic Prescribing in Nepal}

Nepal has received a provision of using a patented medicine without any royalty till July 01,2034 , through the Trade-Related Aspects of Intellectual Property Rights (TRIPS) agreement as the country belongs to the least developed country list. ${ }^{29}$ However, mostly offpatent medicines are manufactured in Nepal. Generally, they are available under the brand name or proprietary name (local manufacturer gives brand names for marketing purposes) than under the generic in the Nepalese market. $^{30,31}$ Pharmaceutical companies use various approaches such as attractive brand names, packaging outlook, dosage formulation variation, and apply various marketing schemes, including push sales with bonuses to attract physicians, pharmacists, and patients towards their products through branded prescribing, dispensing and consumption. Studies showed that 90 $95 \%$ of medicines are prescribed in brand name in tertiary care health facilities where patients have the choice to choose generic alternative; whereas, only around $40 \%$ of medicines were found to be prescribed in brand name in governmental healthcare facilities where the government freely supplies the medication, and generally, patients do not have to purchase out of pocket. ${ }^{7,8,30,32}$

On the other hand, the brand-named generics are principally the generic medicines marketed with proprietary names but are not assured to have therapeutic equivalence to originator brands as the bioavailability and bioequivalence (BABE) 
study is not undertaken to claim so. Bioavailability study refers to the amount of drug entering the systemic circulation from administered dosage. ${ }^{33}$ Bioequivalence study assesses the in vivo biological equivalence (at an equivalence rate and extent of drug available at the site of action) of proprietary with the originator product. ${ }^{33}$ So far, only a few products such as adrenaline injection and metronidazole injection, manufactured by a neighbouring country India, have been reported to be bioequivalent, among the marketed products in Nepal. ${ }^{31}$ Submission of the BABE study report has still not been made mandatory for registration and marketing medicines in Nepal; however, many rules and regulations have been formulated for manufacturing, marketing and importing medicines and medicinal items within Nepal. ${ }^{34,35}$ Additionally, even though the medical code of conduct of the Nepal Medical Council (NMC) recommended prescribing in generic name, there is a lack of generic prescribing policy and practice in Nepal. ${ }^{36}$
Government hospitals have requirements to announce tender, quotation, and other procurement notices of medicines in generic names in Nepal. However, only limited hospitals have made regulations to prescribe in generic names, as per the authors' knowledge. Hence, it would be government, hospitals, taxpayers, and medicine consumersfriendly to initiate generic prescribing practices as a pilot trial starting from government hospitals throughout the country.

\section{Possible Pros and Cons of Generic Prescribing in Nepal}

In this present scenario, there will be both positive and negative impacts on patients, pharmacists, prescribers, and pharmaceutical manufacturers, if the government of Nepal strictly develops and implement generic prescribing policy in real practice. Table 1 outlines some of the essential benefits

Table I Consequences of Generic Prescribing

\begin{tabular}{|c|c|c|}
\hline Stakeholders & Possible Pros & Possible Cons \\
\hline Patients & $\begin{array}{l}\text { - Reduced cost of medications. } \\
\text { - Improved adherence to medications due to } \\
\text { convenience in finding prescribed medicines. } \\
\text { - Improved accessibility and availability of medicines } \\
\text { regardless of their socio-economic factors. } \\
\text { - No economic burden for therapeutically equivalent } \\
\text { medicines. }\end{array}$ & $\begin{array}{l}\text { Possibility of therapeutic failure in patients taking narrow } \\
\text { therapeutic index medicine due to fluctuation in plasma drug } \\
\text { concentration. } \\
\text { - Possibility of receiving the substandard products from } \\
\text { pharmacies. } \\
\text { - A paradoxical decrease in adherence with generics because of the } \\
\text { change in pill colour, packaging and labeling. }\end{array}$ \\
\hline Pharmacists & $\begin{array}{l}\text { - An unethical prescription may be revoked. The } \\
\text { professional paradigm shift from prescribers to } \\
\text { pharmacists } \\
\text { - Decreased inventory holding costs. } \\
\text { - Less chances of medication/dispensing errors } \\
\text { particularly for the sound-alike and look-alike } \\
\text { medicines. } \\
\text { - Efficient medication counselling possible. }\end{array}$ & $\begin{array}{l}\text { - Paradigm shift of marketing influence from prescribers to the } \\
\text { - Gharmacist, leading to physicians' dissatisfaction. } \\
\text { and pharmacists. }\end{array}$ \\
\hline Prescribers & $\begin{array}{l}\text { - No need to memorize a variety of the } \\
\text { brands available in the market by the prescribers. } \\
\text { - More transparent relationship will build between } \\
\text { pharmaceutical manufacturers and prescribers. } \\
\text { - Encouraged practice of ethical prescribing. } \\
\text { - Less prescribing errors. } \\
\text { - Easy availability of the prescribed medications. }\end{array}$ & $\begin{array}{l}\text { - Writing multicomponent and fixed combination products may be } \\
\text { tedious for the prescribers. } \\
\text { - Commission-based prescriptions, if any, get hampered. }\end{array}$ \\
\hline $\begin{array}{l}\text { Pharmaceutical } \\
\text { manufacturers }\end{array}$ & $\begin{array}{l}\text { - Allow smaller manufacturers to enter the market in } \\
\text { a more accessible, cheaper and faster way. } \\
\text { opened. } \\
\text { - Concept of BABE studies can be implemented in } \\
\text { Nepal. }\end{array}$ & $\begin{array}{l}\text { - The current push marketing adopted by most pharmaceutical } \\
\text { companies may need reconsideration. } \\
\text { - Competitive market culture developed. } \\
\text { - Working modality of the marketing team of the pharmaceutical } \\
\text { companies in Nepal may need to be changed. }\end{array}$ \\
\hline
\end{tabular}

Notes: Data from these studies. ${ }^{62,63}$ 
and drawbacks of prescribing generic medications among various stakeholders.

\section{Hurdles to Generic Medicine Usage and Generic Prescribing in Nepal}

Generic medicine and generic prescribing are interrelated issues as the factors affecting generic medicine usage eventually affect the generic prescribing practice. Several factors can directly affect generic medicine use and generic prescribing in Nepal, some of which are discussed here with a possible way out.

\section{Generic Medicines and Generic Medicine Prescribing/Substitution Policy}

Many developed countries such as the USA, Finland, and Sweden have generic medicine prescribing and substitution policies and practices. Many of them adopted various approaches such as incentives to pharmacists and prescribers, and promoting the generic named product in the market to promote generic medicine usage and generic prescribing. ${ }^{11,37-39}$ However, low-income countries like Nepal, where generic prescribing is very essential to reduce economic burden, are still not able to develop and implement generic prescribing and generic substitution policies. Pharmacists are not allowed to substitute with generic equivalents in Nepal yet. ${ }^{40}$ On the other hand, the country also lacks BABE analysis of medicines to assure the interchangeability of available brand-named generic medicines manufactured by different pharmaceuticals in Nepal due to the lack of well-equipped facilities, including reference preparations, competency, and economic constraints to perform in-vivo studies. ${ }^{31}$ Thus, this has ultimately demotivated generic medicine usage, generic prescribing and substitution policy and practice.

However, even amidst this dire constraint, the DDA should efficiently monitor and strictly implement the criteria already formulated ${ }^{34,35}$ and progressively improvise the standards to promote the clinicians' assurance towards using generic alternatives, generic prescribing and substitution of available brand-named generics inside the country to reduce the financial burden and inconvenience to patients. On the other hand, while advocating the generic substitution, one should also bear in mind that generic substitution should not be performed for a few narrow therapeutic index medicines such as antiepileptic agents, immunosuppressants, digoxin and biological products due to safety issues. ${ }^{41,42}$
Recently, the DDA and the Institute of Medicine (Tribhuvan University) reached an agreement to create a bioequivalence center at Maharajgunj Medical Campus to assess the quality of generic pharmaceuticals. ${ }^{43}$ However, the real functioning and implementation of generic medication development in the market remain questionable.

\section{Awareness of Generic Medicine}

Prescribers and dispensers can substantially influence the promotion of generic medicine through generic prescribing and generic substitution by enhancing patients' knowledge and acceptance of generic medicines. ${ }^{44,45}$ However, prescribers are not much aware of generic medicines and their quality standards. ${ }^{31}$ On the other hand, Nepalese customers have low health literacy, ${ }^{46}$ and do not have sufficient knowledge and awareness of generic medicines. They even do not clearly understand the medical terminologies, names of medications being prescribed, dose and administration schedule of prescribed medicines ${ }^{7}$; thus, they rely entirely on the prescribers, pharmacists, nurses, and other healthcare professionals (HCPs), regardless of whether the medicines can be substituted by generic alternative or not. They do not have many options to choose medications themselves, highlighting the necessity of generic medicine intervention at both the HCPs' and general population's levels. The attitude and opinions of HCPs, including physicians and pharmacists, must be improved to implement generic medicine prescribing policy effectively. ${ }^{47}$ Contradictorily, even the medical students and interns were seen to have minimal understanding and negative attitude toward generic medicines and prescribing thereof. ${ }^{48}$ Therefore, it is high time that the concept of generic medicine is added to their respective curricula both at undergraduate and postgraduate levels. Also, the regulatory authorities, in collaboration with various professional councils such as Nepal Medical Council (NMC), Nepal Pharmacy Council (NPC), Nepal Nursing Council (NNS), and Nepal Health Professionals' Council (NHPC), must develop a generic medicine awareness program among HCPs to promote the generic medicine utilization through generic prescribing and dispensing effectively.

Overall, policymakers, pharmacy owner and hospital managers are the key authorities directly affecting pharmaceuticals' selection, distribution, and consumption. However, the lack of awareness of generic medicines has further contributed to generic retrograde medicine prescribing and promotion practices. 


\section{Performance of Regulatory Authorities}

Studies have reported multitudes of substandard medicinal products in the Nepalese market, and about one-third of these fail to meet the requirements of quality standards. ${ }^{49,50}$ Therefore, prescribers are reluctant to prescribe generic medicines and prefer to prescribe specific brand names on which they have trust, irrespective of the exact scientific basis behind such faith. Thus, to promote generic prescriptions in the country, the DDA must first ensure that medicines currently available on the market are safe and of the required quality. Although generic medicines are, by principle, therapeutically equivalent with uniform quality and safety and are interchangeable in terms of quality, safety and efficacy, ${ }^{51}$ the current scenario is nearly 180 degrees opposite in the country. Therefore, DDA should develop a stringent registration system with mandatory evidence of BABE studies and reports for all product ranges for every manufacturer.

Similarly, Nepal Medicines Laboratory (NML), the government-owned national reference laboratory in Nepal, and other NML-approved laboratories must routinely evaluate the random samples of the marketed products to ensure quality, efficacy, and bioequivalence of generic medicines. Additionally, inspection, postmarketing development, and a continuous monitoring system should be set up even after generic medicines' registration and marketing authorization. This will enhance clinicians' confidence in generic prescribing and prevent apathy in generic substitution.

On the other side, the country's drug regulatory framework suffers from a paucity of human resources (including drug inspectors) and foundations, ill-equipped medicine testing laboratories and a lack of reliable drug information and databases. ${ }^{31,52}$ All of these hinders the successful implementation of policy and practice of generic prescribing in the country.

\section{Medicine Prescribing Practice in Nepal}

A systematic review of 2015 showed that healthcare professionals, including doctors, have significant negative perception on generic medicines, ${ }^{53}$ but this area is underreported in Nepal, and many prescribers prefer to prescribe in brand names and very rarely in generic in Nepal. ${ }^{30,32,54}$ The reason to prescribe brand names is due to the enticement from the pharmaceutical firms to do so. However, this practice is crucial as there is a common trend among the public to undoubtedly follow the doctors' recommendations on medication-related issues in Nepal. Similarly, the availability and marketing of medicines in brand names creates confusion and difficulty among patients to understand these issues. Therefore, these directly or indirectly create an environment for commissionbased prescribing and curtail patients' convenient opportunities to select cost-effective generic alternatives. In addition, it often troubles patients to search for a particular brand and pay more incurred by high price variation among different brand alternatives. ${ }^{7,8,32}$ So, strengthening the generic prescribing policy and practices can eradicate their confusion and facilitate their access to cost-effective generic alternatives.

At the same time, switching directly to generic medicines without convincing the prescribers may also be equally problematic as they may think that their right to choose the brands has been seized and transferred to dispensers. However, the code of ethics and professional conduct, 2017, of NMC, instructs medical doctors to prescribe medications in generic name. ${ }^{36}$ Therefore, proper education and motivation to clinicians on generic medicine prescribing and stringent implementation of the code of conduct is essential to promote generic prescribing. Similarly, the role of pharmacy professionals in assuring the availability and accessibility of quality medicines, and the role of clinicians in appropriate selection and prescribing of medicines must be well defined and implemented in practice, avoiding professional infringement.

\section{Medicine Promotion Practice in Nepal}

Pharmaceutical advertisements and promotional activities in Nepal are accomplished by medical or sales representatives (MRs) on behalf of pharmaceutical manufacturers. Majority of them are from non-pharmaceutical backgrounds, have less understanding of medicine and pharmacotherapy, and are more focused on their products' sales and brand promotion. They provide private retail drugstores with substantial incentives, bonuses, and profit margins in exchange for encouraging the sales volume of their specific brands. ${ }^{11,31}$ Pharmaceutical companies in Nepal routinely sponsor medical conferences and even organize parties for the prescribers in the pretence of continuing medical education (CME) ${ }^{45}$ Ansari et al also stated a growing import of expensive brands like calcium and irons, prescribed by doctors with no additional advantages over locally available brands in the Nepalese market. ${ }^{55}$ It is expected that drug prices can drop by up to $30 \%$ if the practice of providing gifts, commissions, and travel allowances to prescribers is effectively abolished. ${ }^{55}$ Some studies reported that prescribers had significantly been influenced by pharmaceutical companies' drug advertising 
schemes that encouraged them to prescribe their brands, irrespective of their real quality and financial burden incurred to the patients. ${ }^{45,48,56}$ Due to these illicit promotional practices among doctors and pharmaceutical manufacturers, patients have been forced to purchase medicine at arbitrarily high costs irrespective of the opportunity to receive cost-effective generic alternatives.

DDA had developed the ethical promotion guideline in 2007 to promote ethical marketing of pharmaceuticals in the country. ${ }^{57}$ However, the malpractices are still not under control, and practical application of the guideline is doubtful. A study conducted in 2020 showed that pharmaceutical corporations' promotional activities violated ethical standards of the WHO and Health Action International (HAI).$^{58}$ In reality, these promotional materials are primarily intended to promote the drugs' brand names and rarely contain helpful information about drugs, such as adverse effects, drug interactions, and usage alerts during pregnancy and breastfeeding. ${ }^{58,59}$ Unethical advertising schemes of pharmaceutical manufacturers and the DDA's inefficiency in controlling unethical advertising are the foremost contributing factors to brand promotion and prescribing in the country. ${ }^{60}$ To date, only a few hospitals such as Dhulikhel hospital, Patan hospital, and Palpa Mission Hospital in Nepal have achieved partial success in implementing generic prescribing practices. Also, KIST Hospital initiated a joint conference practice on a stipulated day of a week to restrict the unethical brand promotion through an individual doctor-MR syndicate. DDA and hospitals themselves have to enact strict regulations and restrictions against unnecessary prescribing and promotion of a particular brand name, and monitor ethical promotion of products and promote a generic medicine development and prescribing practice.

\section{Medicine and Therapeutic Committees in Hospitals}

Medicine and Therapeutic Committee (MTC), a multidisciplinary committee of healthcare professionals recommended by the WHO and Hospital Pharmacy Service Guideline of Nepal, 2015, is mainly responsible for selecting and utilizing medication inside the hospital. ${ }^{64,65}$ Therefore, they can play a significant role in promoting generic medicine and disseminating unbiased information on medicines to HCPs within hospitals, but most hospitals in Nepal do not have actively functioning MTC. In addition, MTC can develop generic procurement and prescribing policy, hospital formulary focusing on cost-effective generic alternatives and provide approval to generic substitution inside the hospital. Therefore, strengthening the MTC in hospitals can significantly resolve generic prescribing and medicine-related issues. Furthermore, generic prescribing with electronic prescribing can also curb uncontrolled brand promotion activities.

\section{Miscellaneous}

Drug Information Centre (DIC) is essential to provide accurate information on generic medicines to the general public and HCPs. ${ }^{61}$ The regulatory body must scrutinize publicly available information and disseminate through MRs of pharmaceutical industries or other means as biased and false information can mislead the rational pharmacotherapy practices. Medical students also realize the need for accurate and unbiased information on the safety and efficacy of medicines. ${ }^{48}$ Therefore, establishing a national DIC may help minimize or prevent misleading information and facilitate disseminating unbiased, accurate and objective medicine information to the public and HCPs; and the DDA is an authorized governmental body to initiate this.

\section{Conclusion}

The promotion of generic medications and generic prescribing can significantly benefit patients and the overall medical fraternity, specifically in terms of cost and overall reduction of medication errors and burden. However, the assurance of quality, safety and efficacy of medicine remains the foremost concern in promoting generic medications and generic prescribing in Nepal. Hence, regulatory authorities should promote equipping the pharmaceutical industries and only allow the marketing of generic pharmaceuticals of optimum quality and efficacy with an assurance of therapeutic equivalence. Immediate action is required to facilitate and implement BABE studies to assure interchangeability. The second stage involves educating HCPs (including physicians and pharmacists) and medical students on the importance of generic medicines to patients' lives and the overall healthcare system, encouraging them to prescribe generically. The generic prescribing strategy would not be practicable without the appropriate arrangement of awareness and assurance of proven quality and therapeutic equivalence of marketed medicines with generic medicine. The study recommends the regulatory authority to promptly enact the generic prescribing and generic substitution policy through strengthening policies and laboratory testing to assure citizens' right to access cost-effective, affordable quality medicine as per the national health and drug policies. 


\section{Acknowledgments}

The authors would like to acknowledge Dr Saval Khanal from the University of Warwick, United Kingdom, for his constructive review while drafting the manuscript.

\section{Disclosure}

Dr Akihiko Ozaki reports personal fees from MNES Inc, outside the submitted work. The authors declared no other potential conflicts of interest with respect to the research, authorship, and/or publication of this article.

\section{References}

1. Ministry of Health and Population. MoHP. National Health Policy 2019, Government of Nepal. 2019:76.

2. DDA. National drug policy-1995, Department of Drug Administration, Nepal; 1995. Available from: http://www.dda.gov. np/content/national-drug-policy-1995. Accessed January 7, 2022.

3. Government of Nepal. The constitution of Nepal 2015. Nepal Gaz. 2015;2015:Art.58.

4. United Nations HumanRrights. Access to medicines - a fundamental element of the right to health. Available from: https://www.ohchr.org/en/ issues/development/pages/accesstomedicines.aspx. Accessed June 3, 2021.

5. Ministry of Health and Population. Nepal national health accounts 2012/13 to 2015/16, Government of Nepal; 2018:123. Available from: www.searo.who.int/entity/nepal/documents/nepal_nha_2012 13_2015_16_mohp_june_2018.pdf. Accessed January 7, 2022.

6. Global spending on health: a world in transition; 2019. Available from: https://www.who.int/publications/i/item/WHO-HIS-HGFHFWorkingPaper-19.4. Accessed June 3, 2021.

7. Aryal A, Dahal A, Shrestha R. Study on drug use pattern in primary healthcare centers of Kathmandu valley. SAGE Open Med. 2020;8:205031212092643. doi:10.1177/2050312120926437

8. Karki KB, Aryal KK, Gyawali P, et al. Quality of drugs and drug use patterns at different level of health care settings in Nepal; 2017. Available from: http://nhrc.gov.np/wp-content/uploads/2017/11/ Final_Drug.pdf. Accessed January 7, 2022.

9. Government of Nepal. Free essential drug for health institution. Available from: https://www.publichealthupdate.com/list-of-free-essential-drugsfor-health-institutions-nepal/. Accessed January 7, 2022.

10. Ide N, LoGerfo JP, Karmacharya B. Barriers and facilitators of diabetes services in Nepal: a qualitative evaluation. Health Policy Plan. 2018;33(4):474-482. doi:10.1093/heapol/czy011

11. Hassali MA, Alrasheedy AA, McLachlan A, et al. The experiences of implementing generic medicine policy in eight countries: a review and recommendations for a successful promotion of generic medicine use. Saudi Pharm J. 2014;22(6):491-503. doi:10.1016/j.jsps.2013.12.017

12. Pharmaphorum. How generic medicines increase patient access to treatment; 2020. Available from: https://pharmaphorum.com/viewsand-analysis/how-generic-medicines-increase-patient-access-totreatment/. Accessed December 11, 2021.

13. Gashaw T, Sisay M, Mengistu G, Amare F. Investigation of prescribing behavior at outpatient settings of governmental hospitals in eastern Ethiopia: an overall evaluation beyond World Health Organization core prescribing indicators. $J$ Pharm Policy Pract. 2018;11(1):1-11. doi:10.1186/S40545-018-0152-Z/TABLES/7

14. Yilma Z, Liben M. Assessment of drug prescription pattern in Mekelle General Hospital, Mekelle, Ethiopia, using World Health Organization prescribing indicators. Biomed Res Int. 2020;2020:1-6. doi:10.1155/2020/3809157
15. Gupta SK, Nayak RP, Vidyarthi SK, et al. KAP of generic medicines among doctors. Natl J Physiol Pharm Pharmacol. 2015;5:39-44. doi:10.5455/njppp.2015.5.170720141

16. Najmi MH, Hafiz RA, Khan I, Fazli FR. Prescribing practices: an overview of three teaching hospitals in Pakistan. Pakistan Medical Assoc. 1998;48(3):73-77

17. Aravamuthan A, Arputhavanan M, Subramaniam K, et al. Assessment of current prescribing practices using World Health Organization core drug use and complementary indicators in selected rural community pharmacies in Southern India. J Pharm Policy Pract. 2016;10(1):1-6. doi:10.1186/S40545-016-0074-6/TABLES/6

18. Atif M, Malik I, Mushtaq I, et al. Medicines shortages in Pakistan: a qualitative study to explore current situation, reasons and possible solutions to overcome the barriers. BMJ Open. 2019;9(9):e027028. doi:10.1136/BMJOPEN-2018-027028

19. Malik A. Prescribe medicines with generic and not brand names, DRAP tells Pakistan's doctors; 2021. Available from: https://www. geo.tv/latest/346083-prescribe-medicines-with-generic-and-not-brand -names-drap-tells-pakistans-doctors. Accessed December 13, 2021.

20. World Health Organization.WHO Expert Committee on Specifications for Pharmaceutical Preparations. World Health Organization Technical Report Series. 1993:834.

21. Desai RJ, Sarpatwari A, Dejene S, et al. Comparative effectiveness of generic and brand-name medication use: a database study of us health insurance claims. PLoS Med. 2019;16(3):e1002763. doi:10.1371/ journal.pmed.1002763

22. Tian Y, Reichardt B, Dunkler D, et al. Comparative effectiveness of branded vs. generic versions of antihypertensive, lipid-lowering and hypoglycemic substances: a population-wide cohort study. Sci Rep. 2020;10(1):1-12. doi:10.1038/s41598-020-62318-y

23. Cameron A, Mantel-Teeuwisse AK, Leufkens HGM, et al. Switching from originator brand medicines to generic equivalents in selected developing countries: how much could be saved? Value Health. 2012;15(5):664-673. doi:10.1016/j.jval.2012.04.004

24. Baumgärtel C. Myths, questions, facts about generic drugs in the EU. Generics Biosimilars Initiat J. 2012;1(1):34-38. doi:10.5639/ gabij.2012.0101.009

25. Ministry of Health and Population. Drug Bulletin of Nepal, Department of Drug Administration, Nepal. Ministry of Health and Population. 2018:29.

26. Aarthiknews. Govt to fix medicine price, generic name of medicine obligatory. Available from: http://english.aarthiknews.com/111882govt-to-fix-medicine-price-generic-name-of-medicine-obligatory. Accessed June 3, 2021.

27. DDA. Role of DDA, Department of Drug Administration, Nepal. Available from: https://www.dda.gov.np/content/role-of-dda. Accessed June 3, 2021.

28. Pandey PJ. Generic medicine is the future - the Himalayan times. Available from: https://thehimalayantimes.com/blogs/genericmedicine-is-the-future. Accessed June 11, 2021.

29. The Rising Nepal. TRIPS transition period for LDC extended till 2034; 2021. Available from: https://risingnepaldaily.com/main-news /trips-transition-period-for-ldc-extended-till-2034. Accessed October 23, 2021.

30. Khanal DP, Adhikari P, Chapagain S, et al. Generic prescribing, brand and generic substitution, availability and cost effectiveness of the available medicines. J Manmohan Meml Inst Health Sci. 2018;4 (1):33-42. doi:10.3126/jmmihs.v4i1.21142

31. Shankar PR, Hassali MA, Subish P, et al. GenMed 010: a one day workshop on generic medicines. Australas Med J. 2011;4 (3):133-135. doi:10.4066/AMJ.2011.587

32. Shrestha R, Prajapati S. Assessment of prescription pattern and prescription error in outpatient Department at Tertiary Care District Hospital, Central Nepal. J Pharm Policy Pract. 2019;12(1):16. doi:10.1186/s40545-019-0177-y 
33. Hema Nagadurga D. Bioavailability and bioequivalence studies. In: Pharmaceutical Formulation Design - Recent Practices. IntechOpen; 2020. doi10.5772/intechopen. 85145

34. DDA. Medicine registration guidance 2073, Department of Drug Administration, Nepal; 2016. Available from: https://pharmainfone pal.com/wp-content/uploads/2020/12/Medicine-registration-guidance -2073.pdf. Accessed August 23, 2021.

35. DDA. Drug registration regulation 2038, Department of Drug Administration, Nepal. Available from: https://www.dda.gov.np/con tent/drug-registration-regulation-2038. Accessed June 3, 2021.

36. NMC. Nepal medical council code of ethics. Nepal Medical Council; 2017. Available from: https://nmc.org.np/nmc-code-of-ethics. Accessed January 7, 2022.

37. Republic S, France I. Share of generic market for pharmaceuticals. Health A Glance Eur. 2016;1(2):182-183. doi:10.1787/health_glance_eur-2016-64-en

38. Dylst P, Vulto A, Simoens S. Demand-side policies to encourage the use of generic medicines: an overview. Expert Rev Pharmacoeconomics Outcomes Res. 2013;13(1):59-72. doi:10.1586/erp.12.83

39. Mostafa S, Mohammad MA, Ebrahim J. Policies and practices catalyzing the use of generic medicines: a systematic search and review. Ethiop J Health Sci. 2021;31(1):167-178. doi:10.4314/ejhs.v31i1.19

40. Ministry of Health and Population. Nepal pharmaceutical country profile. Government of Nepal; 2011. Available from: https://www. who.int/medicines/areas/coordination/nepal_pharmaceutical_profile. pdf. Accessed June 16, 2021.

41. Paveliu MS, Bengea S, Paveliu FS. Generic substitution issues: brand-generic substitution, generic-generic substitution, and generic substitution of narrow therapeutic index (NTI)/critical dose drugs. Maedica. 2011;6(1):52.

42. Macdougall IC, Casadevall N, Locatelli F, et al. Incidence of erythropoietin antibody-mediated pure red cell aplasia: the Prospective Immunogenicity Surveillance Registry (PRIMS). Nephrol Dial Transplant. 2015;30(3):451. doi:10.1093/NDT/GFU297

43. The Kathmandu Post. Maharajgunj Medical Campus to have drug quality test centre. Available from: https://kathmandupost.com/ national/2018/12/31/maharajgunj-medical-campus-to-have-drugquality-test-centre. Accessed August 7, 2020.

44. Stewart K, Alrasheedy A, Hassali A, et al. Patient knowledge, perceptions, and acceptance of generic medicines: a comprehensive review of the current literature. Patient Intell. 2014;49(14):1. doi:10.2147/pi.s46737

45. Giri BR, Shankar PR. Learning how drug companies promote medicines in Nepal: an educational initiative looks critically at the drug industry's promotional tactics. PLoS Med. 2005;2(8):0710-0711. doi:10.1371/journal.pmed.0020256

46. Budhathoki SS, Pokharel PK, Good S, et al. The potential of health literacy to address the health related UN sustainable development goal 3 (SDG3) in Nepal: a rapid review. BMC Health Serv Res. 2017;17(1):1-13. doi:10.1186/s12913-017-2183-6

47. Dunne SS, Dunne CP. What do people really think of generic medicines? A systematic review and critical appraisal of literature on stakeholder perceptions of generic drugs. BMC Med. 2015;13:1. doi:10.1186/s12916-015-0415-3

48. Gyawali S, Hassali MA, Saha A. A survey exploring the knowledge and perceptions of senior medical students in Nepal toward generic medicines. SAGE Open Med. 2016;4:205031211666257. doi:10.1177/2050312116662570
49. Gyanwali P, Humagain BR, Aryal KK, et al. Surveillance of quality of medicines available in the Nepalese market: a study from Kathmandu valley. J Nepal Health Res Counc. 2015;13(31):233-240.

50. Neupane A, Bastakoti M, Tamang S, et al. Incidences of poor-quality pharmaceutical products in Nepal [Preprint]. medRxiv. 2021. doi:10.1101/2021.04.15.21255541

51. USFDA. Generic Drugs: Questions \& Answers. United States Food and Drug Administration. Available from: https://www.fda.gov/ drugs/questions-answers/generic-drugs-questions-answers\#q2

52. myReupublica. Govt indifferent to restructuring and empowering DDA in federalism, the Republica Daily. Available from: https://myrepublica. nagariknetwork.com/news/govt-indifferent-to-restructuring-andempowering-dda-in-federalism/. Accessed June 11, 2021.

53. Colgan S, Faasse K, Martin LR, et al. Perceptions of generic medication in the general population, doctors and pharmacists: a systematic review. BMJ Open. 2015;5:12. doi:10.1136/bmjopen-2015-008915

54. Ghimire S, Nepal S, Bhandari S, et al. A prospective surveillance of drug prescribing and dispensing in a teaching hospital in western Nepal. J Pak Med Assoc. 2009;59(10):726-731.

55. Ansari M, Humagain B, Hassali MA. Generic medicines utilizations and generic prescribing in Nepal: a reflection of current scenario and possible solutions. Res Soc Adm Pharm. 2017;13(3):658-659. doi:10.1016/j.sapharm.2017.01.004

56. Napit PR. Promotional efforts of pharmaceutical industries on prescribing pattern of antibiotics among medical doctors in Nepal. J Bus Soc Sci Res. 2018;1(2):201. doi:10.3126/jbssr.v1i2.20925

57. Harper I, Rawal N, Subedi M. Disputing distribution: ethics and pharmaceutical regulation in Nepal. Stud Nepali Hist Soc. 2011;16 (1):1-39.

58. Jha N, Sapkota Y, Shankar PR. Critical evaluation of drug advertisements in a medical college in Lalitpur, Nepal. J Multidiscip Healthc. 2020;13:717-725. doi:10.2147/JMDH.S259708

59. Alam K, Shah AK, Ojha P, et al. Evaluation of drug promotional materials in a hospital setting in Nepal. South Med Rev. 2009;2(1):2-6.

60. Lee Ventola C. Direct-to-consumer pharmaceutical advertising therapeutic or toxic? P T. 2011;36(10):669-684.

61. Shrestha S, Khatiwada AP, Gyawali S, Shankar PR, Palaian S. Overview, Challenges and Future Prospects of Drug Information Services in Nepal: A Reflective Commentary. $J$ Multidiscip Healthc. 2020;13:287-295 https://doi.org/10.2147/JMDH.S238262.

62. Razmaria AA. Generic drugs. JAMA. 2016;315(24):2746. doi:10.1001/jama.2016.3990

63. USFDA. Generic drug facts. United States Food and Drug Administration. Available from: https://www.fda.gov/drugs/genericdrugs/generic-drug-facts. Accessed August 7, 2020.

64. DDA. Hospital Pharmacy Guideline 2072, Department of Drug Administration, Nepal; 2015. Available from: https://www.dda.gov. $\mathrm{np} /$ content/hospital-pharmacy-guideline-2072. Accessed August 23, 2021.

65. WHO. Drug and Therapeutics Committees A Practical Guide, World Health Organiztion; 2003. Available from: https://apps.who.int/iris/ bitstream/handle/10665/68553/WHO_EDM_PAR_2004.1.pdf? sequence $=1$ \&isAllowed $=\mathrm{y}$. 


\section{Publish your work in this journal}

The Journal of Multidisciplinary Healthcare is an international, peerreviewed open-access journal that aims to represent and publish research in healthcare areas delivered by practitioners of different disciplines. This includes studies and reviews conducted by multidisciplinary teams as well as research which evaluates the results or conduct of such teams or healthcare processes in general. The journal

covers a very wide range of areas and welcomes submissions from practitioners at all levels, from all over the world. The manuscript management system is completely online and includes a very quick and fair peer-review system. Visit http://www.dovepress.com/testimonials. php to read real quotes from published authors. 